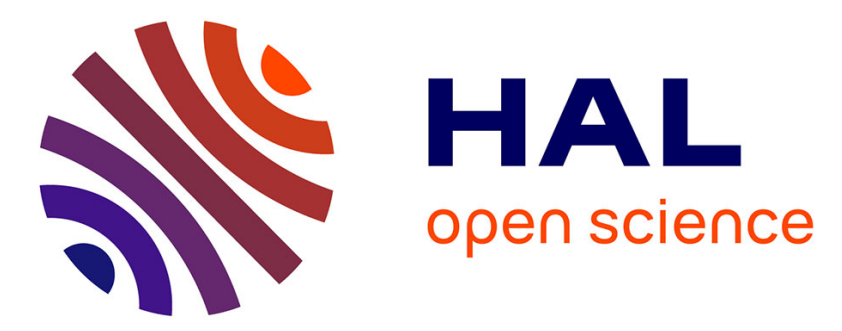

\title{
Determinants of Activity in Glutaredoxins: An in vitro evolved Grx1-like Variant of E. coli Grx3
}

Tobias H Elgán, Anne-Gaëlle Planson, Jon Beckwith, Peter Güntert, Kurt D Berndt

\section{- To cite this version:}

Tobias H Elgán, Anne-Gaëlle Planson, Jon Beckwith, Peter Güntert, Kurt D Berndt. Determinants of Activity in Glutaredoxins: An in vitro evolved Grx1-like Variant of E. coli Grx3. Biochemical Journal, 2010, 430 (3), pp.487-495. 10.1042/BJ20100289 . hal-00512005

\section{HAL Id: hal-00512005 \\ https://hal.science/hal-00512005}

Submitted on 27 Aug 2010

HAL is a multi-disciplinary open access archive for the deposit and dissemination of scientific research documents, whether they are published or not. The documents may come from teaching and research institutions in France or abroad, or from public or private research centers.
L'archive ouverte pluridisciplinaire HAL, est destinée au dépôt et à la diffusion de documents scientifiques de niveau recherche, publiés ou non, émanant des établissements d'enseignement et de recherche français ou étrangers, des laboratoires publics ou privés. 


\title{
Determinants of Activity in Glutaredoxins: An in vitro evolved Grx1-like Variant of $E$. coli Grx3
}

\author{
Tobias H. Elgán, ${ }^{\star \dagger}{ }^{\S 1}$ Anne-Gaëlle Planson, ${ }^{\ddagger}$ Jon Beckwith $^{\ddagger}$, Peter Güntert,,$\| \rrbracket$ \\ and Kurt D. Berndt ${ }^{*}$ \\ *Department of Biosciences and Nutrition, Karolinska Institutet, NOVUM, S-141 57 Huddinge, \\ Sweden \\ ${ }^{\dagger}$ School of Life Sciences, Södertörns Högskola, S-141 89 Huddinge, Sweden \\ ${ }^{\ddagger}$ Department of Microbiology and Molecular Genetics, Harvard Medical School, Boston, MA 02115, \\ USA

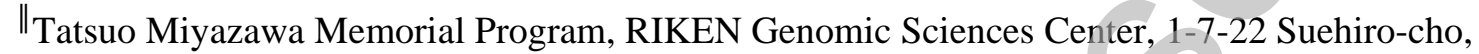 \\ Tsurumi, Yokohama 230-0045, Japan \\ "Institute of Biophysical Chemistry and Frankfurt Institute for Advanced Studies, Max-von-Laue- \\ Straße 9, Goethe-University Frankfurt, 60438 Frankfurt am Main, Germany \\ ${ }^{ \pm}$Graduate School of Science, Tokyo Metropolitan University, 1-1 Minami-ohsawa, Hachioji, Tokyo \\ 192-0397, Japan \\ ${ }^{\S}$ Current addresses: \\ T.H.E. - STAD, Stockholm Center for Psychiatric Research and Education, Department of Clinical \\ Neuroscience, Stockholm County Council Health Care Provision and Karolinska Institutet, Box 6031, \\ S-102 31 Stockholm, Sweden \\ A.G.P. - Institut de Biologie et Technologies - Saclay iBiTecs CEA-Saclay, Bat 14291191 Gif-sur- \\ Yvette, France
}

Key words: glutaredoxin, ribonucleotide reductase, ligand-induced stability, NMR, chemical shift, H/D exchange

\begin{abstract}
Abbreviations used: Trx, thioredoxin; Grx, glutaredoxin; RR, ribonucleotide reductase; RRp, E. coli ribonucleotide reductase peptide comprising residues 1737-1761 (C754S); GS-protein, glutathioneprotein; $\beta$ Me, $\beta$-mercaptoethanol, PAPS, 3'-phosphoadenylylsulfate; $V_{\max }$, maximum velocity of enzyme catalyzed reaction; $K_{\mathrm{m}}$, Michaelis constant; $C D$, circular dichroism; $\Delta G_{H_{2} O}$, Gibbs free energy in absence of denaturant; $\Delta \Delta G_{H 2 O}$, difference in conformational stability between two proteins; $\left[\right.$ Urea $_{1 / 2}$, midpoint of urea unfolding reaction; NMR, nuclear magnetic resonance; HSQC, heteronuclear single quantum coherence.
\end{abstract}

${ }^{1}$ To whom correspondence should be addressed: Tobias H. Elgán, STAD, Stockholm Center for Psychiatric Research and Education, Department of Clinical Neuroscience, Stockholm County Council Health Care Provision and Karolinska Institutet, Box 6031, S-102 31 Stockholm, Sweden, Tel: +46 (0)8 123455 21, Fax: +46 (0)8 123455 09, E-mail: tobias.elgan@sll.se

Running title: Structure and dynamics explaining the Grx1-like activity of Grx3(M43V) 


\section{SYNOPSIS}

The E. coli glutaredoxins 1 and 3 (Grx1 and Grx3) are structurally similar (37\% sequence identity), yet have different activities in vivo. Unlike Grx3, Grx1 efficiently reduces protein disulfides in proteins like ribonucleotide reductase (RR), while being poor at reducing S-glutathionylated proteins. An E. coli strain lacking genes encoding thioredoxins 1 and 2 and Grx1 is not viable on either rich or minimal medium, however, a M43V mutation in Grx3 restores growth under these conditions and results in a Grx1-like protein [Ortenberg, R., et al. (2004) PNAS 101, 7439-44]. To uncover the structural basis of this change in activity, we have compared wild type and mutant Grx3 using CD and NMR spectroscopy. Ligand-induced stability measurements demonstrate that the Grx3(M43V/C65Y) mutant has acquired affinity for RR. Far-UV CD spectra reveal no significant differences, but differences are observed in the near-UV region indicative of tertiary structural changes. NMR ${ }^{1} \mathrm{H}_{-}{ }^{15} \mathrm{~N}$ HSQC spectra show that approximately half of the 82 residues experience significant $(\Delta \delta>0.03 \mathrm{ppm})$ chemical shift deviations in the mutant, including 9 residues experiencing extensive $(\Delta \delta \geq 0.15 \mathrm{ppm})$ deviations. To test if the M43V mutation alters dynamic properties of Grx3, H/D exchange experiments were performed demonstrating that the rate at which backbone amides exchange protons with the solvent is dramatically enhanced in the mutant - particularly in the core of the protein. These data suggest that the Grx1-like activity of the Grx3(M43V/C65Y) mutant may be explained by enhanced intrinsic motion allowing for increased specificity towards larger substrates such as RR.

\section{INTRODUCTION}

The glutaredoxins are ubiquitous enzymes found in virtually all life forms from plants and viruses to humans. They are members of the thioredoxin (Trx) superfamily characterized by a common tertiary structure, the thioredoxin fold [1], and a highly conserved -C-X-X-(C/S)- active site motif [2]. By utilizing the redox properties of these active site cysteines, the glutaredoxins participate in reversible disulfide bond formation thereby protecting cells against oxidative stress [3], and having a profound impact on cellular functions, affecting, for example, enzymatic activity and regulatory pathways [4-5]. It has been proposed that the glutaredoxins exert their catalytic activity via a monothiol pathway in which only the $\mathrm{N}$-terminal active site cysteine is required to reversibly reduce glutathione(GS)-mixed disulfides and via a dithiol pathway requiring both active site cysteines to reduce low molecular weight and protein disulfides [6].

Four glutaredoxins have been identified in the E. coli genome [7]. The highly abundant 24 $\mathrm{kDa}$ Grx2 and the $13 \mathrm{kDa}$ Grx4 are atypical glutaredoxins in the sense that the former has an additional structural domain making it similar to the glutathione S-transferases, while the latter has a highly conserved monothiol -C-G-F-S- active site sequence [2]. Grx1 and Grx3 (10 and 9 kDa, respectively) are both prototypical glutaredoxins having the classical glutaredoxin -C-P-Y-C- active site sequence and are structurally very similar $[6,8]$ as indicated by their $37 \%$ sequence identity. It has been observed that these glutaredoxins have both overlapping and distinct activities. While Grx1 and 3 both are excellent reductants of GS-protein mixed disulfides [9-10], only Grx1 is capable of efficiently reducing the essential enzyme ribonucleotide reductase (RR) [10-11] and 3'-phosphoadenylylsulfate (PAPS) reductase [12].

A previous study by Ortenberg and co-workers [13] on the differences in substrate specificities amongst the glutaredoxins focused on the E. coli proteins Grx1 and Grx3. Using a PCRprone mutagenesis approach using an E. coli strain missing Trx1 and 2 and Grx1 (all capable of reducing RR), a single site point mutant form of Grx3, which restores bacterial growth, was repeatedly identified. It was found that the affected residue position, Met43 located outside the active site, was mutated into an isoleucine, leucine or valine - the latter having the most prominent effect.

Furthermore, Porat and co-workers [14] characterized the Grx3(M43V) mutant biochemically and by molecular dynamics simulations. These results showed that (i) the altered protein has gained a sevenfold increase in $V_{\max }$ towards reducing RR while leaving the $K_{\mathrm{m}}$ value unaffected, (ii) the $\mathrm{N}$-terminal active site cysteine of the mutant has a 1.1 unit lower $\mathrm{p} K_{\mathrm{a}}$ value, (iii) the redox potential of the active site cysteines is $11 \mathrm{mV}$ more reducing in the mutant protein, and (iv) molecular dynamics simulations demonstrated that the structure of the mutant did not differ from the wild type protein. Altogether, it was concluded that the mutation affects the activity of Grx3 by reducing the N-terminal active site $\mathrm{p} K_{\mathrm{a}}$ value, and thereby lowering the redox potential. 
Previous studies [14-16] have suggested that at least part of the observed difference in activity between Grx1 and Grx3 is related to a greater flexibility in the former. To test this hypothesis and gain insight into the acquired Grx1-like activity caused by the Met43 to Val mutation in Grx3, we have investigated structural and dynamic properties of this mutant. By using CD and NMR spectroscopy, we investigate structural and dynamic changes caused by the M43V mutation in Grx3 which has conferred the Grx1-like activity to the Grx3 enzyme.

\section{EXPERIMENTAL}

\section{Protein expression and purification}

Mutant grxC genes (encoding E. coli Grx3(C65Y) and the C14S/C65Y version) inserted in pET24d (Novagen) vectors, and grxA genes (encoding wild type E. coli Grx1 and the C14S mutant) inserted in pET101D-TOPO vectors (Invitrogen) were available within our laboratory. The Met43 to Val mutation was introduced into the two mutant grxC genes using the QuickChange Kit (Stratagene) and the following primers: 5'-GCC AAG CGT GAA GAG GTG ATC AAA CGC AGC GG-3' and 5'-CCG CTG CGT TTG ATC ACC TCT TCA CGC TTG GC-3'. The vector constructs were transformed into E. coli BL21 Star (DE3) cells (Invitrogen) using standard procedures. The expression, purification and characterization of the Grx1 and Grx3 constructs were performed as described elsewhere [17].

For the NMR measurements, uniformly ${ }^{15} \mathrm{~N}$-labeled Grx3 in both C65Y and M43V/C65Y mutant forms and $\mathrm{a}^{15} \mathrm{~N} /{ }^{13} \mathrm{C}$ doubly labeled M43V/C65Y mutant sample were prepared using the method of Marley and co-workers [18]. Briefly, a starter culture was grown over night in LB medium containing kanamycin ( $\mu \mathrm{g} \mathrm{ml}^{-1}$ ) at $37^{\circ} \mathrm{C}$ and then diluted into 2 liters of LB medium. When $\mathrm{A}_{600}$ reached $\sim 0.8$, cells were harvested by centrifugation for $20 \mathrm{~min}$ at $7000 \mathrm{~g}$, washed with 2 liters M9 minimal medium, centrifuged, and then resuspended in $\mathrm{M} 9$ medium enriched with ${ }^{13} \mathrm{C}$-glucose (or natural abundance glucose) and ${ }^{15} \mathrm{~N}$-ammonium sulfate. The culture was grown at $37^{\circ} \mathrm{C}$ for 1 hour and then induced with IPTG (1 mM final concentration). The culture was incubated over night and then harvested by centrifugation. Protein concentrations were determined by UV-absorbance at $280 \mathrm{~nm}$ using the following extinction coefficients [19]: $5120 \mathrm{M}^{-1} \mathrm{~cm}^{-1}$ for all Grx3 variants $\left(5240 \mathrm{M}^{-1} \mathrm{~cm}^{-1}\right.$ for the corresponding mixed disulfides) and $10810 \mathrm{M}^{-1} \mathrm{~cm}^{-1}$ for the Grx1 variants (10930 $\mathrm{M}^{-1} \mathrm{~cm}^{-1}$ for mixed disulfides).

\section{In vivo activity of Grx3(M43V/C65Y)}

The in vivo activity of the E. coli Grx3(M43V) and M43V/C65Y mutants towards RR was determined as described by Ortenberg et al. [13]. Briefly, a pAG10 plasmid encoding E. coli Grx3(M43V/C65Y) was constructed by site-directed mutagenesis (QuikChange Kit, Stratagene) from a pRO2 plasmid template carrying the $\operatorname{grxC}(\mathrm{M} 43 \mathrm{~V})$ gene encoding Grx3(M43V) [13] under the control of a lacUV5 promoter and tetracycline resistance as a selectable marker. For this purpose, the following primers were used: 5'-GCA CAT TGG CGG CTA TGA TGA CTT GTA C-3' and 5'-GTA CAA GTC ATC ATA GCC GCC AAT GTG C-3'. The pRO2 and the resulting pAG10 plasmids were transformed into E. coli bacteria (strain RO36, DHB4 $\triangle$ trxA $\triangle$ trxC grxA::kan nrdH::spc/pBAD18-trxC) and transferred to separate NZ-amine plates supplemented with $15 \mu \mathrm{g} / \mathrm{ml}$ tetracycline and $0.2 \%$ arabinose to induce Trx2 expression. Selected colonies were picked and transferred to NZ plates supplemented with $0.2 \%$ glucose (to repress Trx2 expression) in the absence and presence of $1 \mathrm{mM}$ IPTG required for the expression of the Grx3 mutant. In the latter condition, only the expression of a Grx3 mutant that is able to reduce RR will be able to restore bacterial growth.

\section{Ligand-induced conformational stability measurements using CD spectroscopy}

Crude ribonucleotide reductase peptide (RRp, residues 737-761 from C754S mutant E. coli ribonucleotide reductase [20]) was purchased (Keck Biotechnology resource center) in the reduced state and purified by RP HPLC (Chemstation 1100, Agilent Technologies) using a C18 semipreparative column (218TPB510, Vydac) by applying a gradient from 10 to $40 \%$ acetonitrile/water ( $0.1 \%$ TFA) in 45 minutes. The peptide was dissolved in $\mathrm{dH}_{2} \mathrm{O}$ and lyophilized several times in a speed-vac (Savant), and finally dissolved in $50 \mathrm{mM}$ phosphate, $50 \mu \mathrm{M}$ EDTA buffer at pH 7.0. RRp$\beta$-mercaptoethanol ( $\beta \mathrm{Me}$ ) mixed disulfide was prepared by incubating reduced RR peptide with a 100- 
fold molar excess 2-hydroxyethyl disulfide (Aldrich) over night followed by HPLC purification as above followed by ESI-MS analysis (Finnigan MAT LCQ).

Grx-RRp mixed disulfides were prepared by incubating reduced protein (typically at a concentration of $\sim 0.2 \mathrm{mM}$ ) over night at $4^{\circ} \mathrm{C}$ with a 20 -fold molar excess of RRp- $\beta$ Me mixed disulfide followed by gel filtration (PD-10, GE Healthcare). Grx-RRp mixed disulfide formation was confirmed by analytical RP-HPLC followed by ESI-MS as above. The preparation of the Grx-SG, and Grx- $\beta \mathrm{Me}$ mixed disulfides have been described elsewhere [17].

Conformational stabilities of proteins in their reduced and corresponding mixed disulfide complexes with RRp, glutathione, and $\beta$ Me were measured by semi-automated unfolding experiments using urea (ICN Biomedicals) and monitored using an Aviv 202 spectropolarimeter (Aviv Biomedical Inc.) equipped with a 2-syringe pipetting robot (Microlab 500, Hamilton). The protein (mixed disulfide) concentrations ranged from 2.5 to $3.4 \mu \mathrm{M}$ and experiments were performed at $25^{\circ} \mathrm{C}$ using the same buffer as above. The unfolding reactions were monitored at $222 \mathrm{~nm}$ as the urea concentration was increased in $0.125 \mathrm{M}$ steps into a stirred quartz cuvette with $1 \mathrm{~cm}$ path length. Samples were allowed to equilibrate for $7 \mathrm{~min}$ after each addition of urea followed by data collection for 30 seconds.

Assuming that the protein unfolding reaction in the presence of a denaturant, $\mathrm{D}$, is a reversible two-state process between the folded (f) and unfolded (u) forms and that the unfolding free energy ( $\Delta G^{\text {Unfold }}$ ) is a linear function of the denaturant concentration [D] and the unfolding free energy in the absence of denaturant ( $\Delta G_{\mathrm{H}_{2} \mathrm{O}}^{\text {Unfld }}$ ), an equation for the experimental observable ( $\mathrm{y}_{\mathrm{obs}}$ ) can be derived as described previously [21-22]:

$$
y_{\text {obs }}=\frac{\left(y_{f}+m_{f}[D]\right)+\left(y_{u}+m_{u}[D]\right) \cdot \exp \left\{\frac{m_{\text {trans }}[D]+\Delta G_{H_{2} \mathrm{O}}^{\text {Unfld }}}{R T}\right\}}{1+\exp \left\{\frac{m_{\text {trans }}[D]+\Delta G_{H_{2} \mathrm{O}}^{\text {Unfold }}}{R T}\right\}}
$$

Eq. 1

Here $y_{o b s}$ is the observed cd signal at 222nm, $m_{\text {trans }}$ is the denaturant dependency of the measured free energy changes of unfolding ( $\Delta G^{\text {Unfold }}$ ); $y_{f}$ and $y_{u}$ are the observed values of the CD signal of fully folded and unfolded forms, respectively; and $m_{f}$ and $m_{u}$ refer to the slopes of the linear pre- and posttransition regions, respectively. Raw data from the urea titration experiments were fitted to Equation 1 using the Levenberg-Marquardt, nonlinear least-squares regression routine in the Igor Pro software package (WaveMetrics). Values describing the conformational stabilities are reported in terms of the folding reaction using the following relationship $\Delta G_{\mathrm{H}_{2} \mathrm{O}}^{\mathrm{Fold}}=-\Delta G_{\mathrm{H}_{2} \mathrm{O}}^{\text {Unfld }}$.

\section{Redox potential determination using thermodynamic linkage}

Reduced Grx3(M43V/C65Y) was prepared as above. The oxidized form was obtained by incubating previously reduced protein in a 50-fold molar excess of GSSG for 1 hour followed by gel filtration (as above). The conformational stability and subsequent analysis of reduced and oxidized Grx3(M43V/C65Y) was determined by urea unfolding monitored by CD spectroscopy as above. Subsequent calculation of the redox potential was performed as previously described $[2,23]$ using the thermodynamic linkage relationship between the stability of a disulfide bond to the stability of a protein containing it [24].

\section{CD wavelength scans}

CD spectra of the proteins in their respective reduced states were collected using an Aviv 62 DS spectropolarimeter (Aviv Biomedical Inc.). The reduced forms of the proteins were prepared by adding a 50-fold molar excess of DTT, which was removed after $1 \mathrm{~h}$ by gel filtration (NAP-5, GE Healthcare). Measurements were performed in degassed $50 \mathrm{mM}$ potassium phosphate, $50 \mu \mathrm{M}$ EDTA, pH 7.0 buffer. Far-UV CD measurements were performed in a $0.01 \mathrm{~cm}$ quartz cuvette (Hellma) between 260 and $180 \mathrm{~nm}$ for 12 seconds every $1.0 \mathrm{~nm}$ using a bandwidth of $1.5 \mathrm{~nm}$. Data were converted into mean residue molar circular dichroism $(\Delta \varepsilon)$ using the relationship $\Delta \varepsilon=[\Theta]_{\mathrm{MRW}} / 3298$, 
where $[\Theta]_{\text {MRW }}$ is the mean residue molar ellipticity. The near-UV CD spectra were measured in a 1.0 cm quartz cuvette (Hellma) between 340 and $250 \mathrm{~nm}$. Data were collected for 8 seconds every $0.3 \mathrm{~nm}$ using a bandwidth of $0.3 \mathrm{~nm}$. Data from the near-UV scans, reported as molar ellipticity $[\Theta]$, were smoothed using a polynomial fitting routine in the Igor Pro software package . The protein concentrations were $\sim 165 \mu \mathrm{M}$ for all far-UV CD measurements and $\sim 140 \mu \mathrm{M}$ for all near-UV measurements.

\section{NMR spectroscopy}

All NMR measurements were performed on a Varian Inova $500 \mathrm{MHz}$ spectrometer (Varian Inc.) at 25 ${ }^{\circ} \mathrm{C}$ using protein concentrations between 1.5 and $3 \mathrm{mM}$ in degassed $50 \mathrm{mM}$ potassium phosphate, 50 $\mu \mathrm{M}$ EDTA, $5 \mathrm{mM}$ DTT buffer at $\mathrm{pH}$ 6.6, containing $5 \% \mathrm{D}_{2} \mathrm{O}$. Sequence-specific resonance assignment of the M43V/C65Y mutant was achieved by using a $\left[{ }^{15} \mathrm{~N},{ }^{1} \mathrm{H}\right]$ HSQC and a set of triple resonance experiments [25] which included HNCA, HN(CO)CA, HNCO, HN(CA)CO, CBCANH, and CBCA(CO)NH. All NMR spectra were processed with the NMRPipe software package [26] and analyzed using the NMRViewJ software (One Moon Scientific, inc.). The resulting peak lists were used as input for automated resonance assignment using the GARANT program [27].

Uniformly ${ }^{15} \mathrm{~N}$-labeled C65Y and M43V/C65Y mutant Grx3 proteins were lyophilized as above. Time correlated Hydrogen/Deuterium (H/D) exchange experiments [28] of exchangeable protons were initiated by the addition of $\mathrm{D}_{2} \mathrm{O}$ to the lyophilized proteins. The $\mathrm{H} / \mathrm{D}$ exchange reaction was followed by collecting series of ${ }^{15} \mathrm{~N}$-HSQC spectra as a function of time. A total of 60 spectra for a period of 28.2 days and 26 spectra during $6.2 \mathrm{~h}$ were collected for the C65Y and the M43V/C65Y mutant proteins, respectively, until all amide proton peaks had disappeared. The spectra were processed as above and the resulting peak volumes determined using the XEASY software [29]. Pseudo first order rate constants were calculated by fitting the resulting data points to a first-order equation using the Igor Pro software package.

\section{RESULTS AND DISCUSSION}

\section{Cys65 of Grx3 has no apparent effect on the reducing ability of ribonucleotide reductase in vivo}

Apart from its two active site cysteines, Grx3 has an additional cysteine (Cys65) located outside the active site which has been found to have homologous counterparts in all but one glutaredoxin subgroup (based on the human glutaredoxins) [2]. This residue has been observed to form intermolecular disulfides in vitro thereby producing homodimers or mixed disulfides [23], complicating structural and functional studies of the active site. This behavior can be avoided by using a C65Y mutant which has essentially identical activity to the wild type protein in vitro [8] and has therefore been used extensively in other studies [8, 17, 23, 30]. Until this work, the in vivo significance of this residue remained uncertain, although it had been demonstrated that a homologous cysteine in the monothiol yeast Grx5 rescued a dithiol-like mechanism (involving two Grx cysteines) [31]. To test if the Cys65 residue has an impact on the in vivo reduction of ribonucleotide reductase [13], Grx3(M43V) and Grx3(M43V/C65Y) mutants were expressed in E. coli that lack the genes encoding proteins capable of reducing ribonucleotide reductase. The ability of the Grx3(M43V/C65Y) mutant to restore bacterial growth to the same extent as the M43V mutant (data not shown) demonstrates that the C65Y mutation does not affect the in vivo activity, as determined by these phenotypes, and justifies the usage of the C65Y version of Grx3.

The following Grx3 variants were used in this study: C65Y (sometimes referred to as wild type), M43V/C65Y, C14S/C65Y, and C14S/M43V/C65Y.

\section{The Grx3(M43V/C65Y) mutant has increased affinity for ribonucleotide reductase}

The free energy of binding of a ligand to a protein gives rise to a change in conformational stability ( $\Delta G_{\mathrm{H}_{2} \mathrm{O}}^{\text {Fold }}$ ) with respect to the unbound form. Depending on how well a ligand interacts with a protein noncovalently, a ligand can either have a stabilizing or destabilizing effect on the protein-ligand complex. This ligand-induced (de)stabilization $(\Delta \Delta \mathrm{G})$ is a measure of ligand affinity, and has proven to be a useful approach to dissect specificity as individual interactions between a protein and a ligand can 
be quantified using a set of ligand analogs [17]. The approach is particularly appropriate for the glutaredoxins since catalysis naturally proceeds via a transiently stable covalent mixed disulfide which can be trapped using a C-terminal active site cysteine to serine variant. A recent study from our lab on Grx3 substrate specificity demonstrated that while the tripeptide glutathione ( $\gamma$-Glu-Cys-Gly) has a stabilizing effect by $0.50 \pm 0.13 \mathrm{kcal} \mathrm{mol}^{-1}$ upon Grx3 mixed disulfide formation, it does not have a significant impact upon complex formation with Grx1 [17] (Table 1). This result correlates with the enzymatic activities of these proteins since Grx3 is more efficient than Grx1 at reducing GS-mixed disulfides $[8,11]$. That thermodynamic properties can be used within the glutaredoxin family as an indicator of enzymatic activity has been demonstrated by others [32]. However, as pointed out by Saaranen and co-workers [32], comparisons between thermodynamic and kinetic properties should be made with caution as these properties are not readily interconvertible. Nevertheless, since previous studies have indicated that the Grx3(M43V/C65Y) mutant acquired an enhanced ability to reduce ribonucleotide reductase, it is feasible to use ligand-induced stability to test for alterations in affinity.

In this study, active site C14S variants of wild type and mutant Grx1 and Grx3 together with a 25-residue peptide from ribonucleotide reductase (RRp, the C1754S mutant of residues 1737-1761) [16] was used. The RRp-peptide has been demonstrated to bind to Grx1 in a specific manner [16], thereby mimicking the intermediate Grx-RR mixed disulfide form. After the formation of 1:1 mixed disulfide complexes between the different glutaredoxin variants and the RRp-peptide, the conformational stabilities of unbound and RRp-peptide bound forms were determined by urea unfolding monitored by CD spectroscopy. As shown in Figure 1 and Table 1, Grx1(C14S) is stabilized by $\left(\Delta \Delta \mathrm{G}_{1}\right) 1.90 \pm 0.21 \mathrm{kcal} \mathrm{mol}^{-1}$ upon mixed disulfide formation with the RRp-peptide. The effect exerted by the M43V mutation on Grx3 affinity to ribonucleotide reductase is apparent as the RRppeptide has no significant impact on the stability of the corresponding Grx3(C14S) complex $\left(\Delta \Delta \mathrm{G}_{1}=0.04 \pm 0.18 \mathrm{kcal} \mathrm{mol}^{-1}\right)$ while the $\mathrm{Grx} 3(\mathrm{C} 14 \mathrm{~S} / \mathrm{M} 43 \mathrm{~V} / \mathrm{C} 65 \mathrm{Y})$ mutant is stabilized by $\left(\Delta \Delta \mathrm{G}_{1}\right) 1.51$ $\pm 0.12 \mathrm{kcal} \mathrm{mol}^{-1}$ upon mixed disulfide formation with RRp. Furthermore, by comparing the Grx mixed disulfides with glutathione and the RRp-peptide to the corresponding $\beta$ Me mixed disulfides, it is possible to quantify how much all interactions between the protein and ligand are worth $\left(\Delta \Delta \mathrm{G}_{2}\right)$. Here it is shown that while the total interactions between glutathione and Grx3(C14S/C65Y) are worth $\left(\Delta \Delta \mathrm{G}_{2}\right)-3.07 \pm 0.13 \mathrm{kcal} \mathrm{mol}^{-1}$, Table 1, the interactions between the same protein and the RRp-peptide amounts to $-2.57 \pm 0.17 \mathrm{kcal} \mathrm{mol}^{-1}$. Thus, the Grx3(C14S/C65Y) protein makes more favorable interactions to glutathione relative the RRp-peptide (by $0.5 \pm 0.21 \mathrm{kcal} \mathrm{mol}^{-1}$ ). Making the same analysis with the corresponding Grx1(C14S) and Grx3(C14S/M43V/C65Y) mixed disulfides with glutathione and RRp reveals that, unlike the Grx3(C14S/C65Y) protein, these two proteins make more favorable interactions with the RRp-peptide by $1.87 \pm 0.25\left(\Delta \Delta \mathrm{G}_{2}=-4.72 \pm 0.17\right.$ versus $\left.-2.85 \pm 0.18\right)$ and $0.21 \pm 0.11 \mathrm{kcal} \mathrm{mol}^{-1}\left(\Delta \Delta \mathrm{G}_{2}=-4.19 \pm 0.09\right.$ versus $\left.-3.98 \pm 0.06\right)$, respectively. It then appears as if the M43V mutation has altered the binding properties of the Grx3 protein as this variant makes stronger interactions with the RRp-peptide and less prominent interactions with glutathione, indicating less activity with regards to reducing S-glutathionylated proteins [17].

The above presented results, however, do not correlate with previous findings. Assuming Michaelis-Menten kinetics, Porat and co-workers reported that an improved $V_{\max }$ rather than $K_{\mathrm{m}}$ was responsible for the Grx1-like behavior of the Grx3(M43V) mutant [14]. What is then the reason for the discrepancy between these results? The $K_{\mathrm{m}}$ value represents an apparent dissociation constant which characterizes the total binding event based on Michaelis-Menten kinetics, including all bound forms of the substrate. When using the $K_{\mathrm{m}}$ value as a measure of affinity it is assumed that the rate-limiting step is the product formation and that any intermediary enzyme-product complex is ignored since dissociation of this complex into enzyme and product is fast. However, it has previously been demonstrated that glutaredoxins have a tendency to form a transiently stable substrate mixed disulfide [2, 23], which makes the interpretation of $K_{\mathrm{m}}$ values in the case of mixed disulfides complex. It is then possible that the previously reported $K_{\mathrm{m}}$ values and the results from the affinity measurement presented here are not comparable since they probe different phenomena (i.e., product formation and protein-substrate binding).

\section{The reducing ability of the Grx3(M43V/C65Y) mutant is improved}


Recently it was reported that the redox potential ( $E^{\circ \prime}$ ) of the Grx3(M43V) mutant was lowered by 11 $\mathrm{mV}$ relative to the wild type protein $(-203 \mathrm{mV}$ and $-192 \mathrm{mV}$, respectively) [14]. It was noted that the value for the wild type protein was $6 \mathrm{mV}$ more oxidizing than the previously reported value $(-198 \mathrm{mV})$ [23], a difference which was rationalized by the fact that the latter measurement was performed on the C65Y variant of Grx3 (the same variant as used in the current study). Thus, it is expected that the M43V/C65Y mutant used here has a redox potential of $-209 \mathrm{mV}(-198-11 \mathrm{mV})$.

To measure the redox potential of the M43V/C65Y mutant, conformational stability measurements of the reduced and oxidized protein were performed. The redox potential of a protein can then be determined based on the fact that the stability of a disulfide is related to the conformational stability of a protein [24] via thermodynamic linkage (Fig. 2). The stabilities of the reduced ( $\Delta G_{H 2 O}^{\text {red }}$ ) and oxidized ( $\Delta G_{H 2 O}^{o x}$ ) mutants were determined to be $-3.01 \pm 0.04$ and $-2.55 \pm 0.06$ $\mathrm{kcal} \mathrm{mol}^{-1}$, respectively (Fig. 2, Table 1). Assuming that the Gibbs free energy of disulfide bond formation in the unfolded state of Grx3(M43V/C65Y) is identical to the wild type ( $\Delta G_{U}^{\text {ssbond }}=-1.01$ $\mathrm{kcal} \mathrm{mol}^{-1}$ [23]) a value of $-1.47 \mathrm{kcal} \mathrm{mol}^{-1}$ is calculated for the Gibbs free energy of disulfide bond formation in the native state ( $\Delta G_{N}^{\text {Ssbond }}$, i.e., redox potential) using thermodynamic linkage (Fig. 2) and the relationship $\Delta G^{\circ \prime}=-n F \Delta E^{\circ \prime}$, where $n$ represents the two electrons transferred in this reaction, and $F$ is the Faraday constant $23040.612 \mathrm{cal} \mathrm{mol}^{-1} \mathrm{~V}^{-1}$ [2]. Applying the standard state glutathione reference of $-240 \mathrm{mV}$, this value amounts to a redox potential value of $-208 \mathrm{mV}$ which agrees closely with the calculated value $(-209 \mathrm{mV})$. Thus, we have confirmed using thermodynamic cycles that the M43V mutation turns Grx3 into a 10-11 mV more reducing protein and that the C65Y mutation increases the redox potential by $6 \mathrm{mV}$.

\section{The M43V mutation has an impact on the overall Grx3 tertiary structure}

To examine if the altered activity of the Grx3(M43V) mutant [13-14] can be rationalized in terms of structural changes, both wild type and the M43V/C65Y variant of Grx3 were probed by CD spectroscopy. CD wavelength scans were collected in both the far- and near-UV regions to probe the secondary and tertiary structures, respectively. As seen in Figure 3, the far-UV CD scans demonstrate that all Grx3 protein constructs (as well as the Grx1 ones) have essentially the same secondary structure content. On the other hand, the near-UV scans reveal distinct differences as the M43V mutation results in a more positive ellipticity in the region of $265-280 \mathrm{~nm}$. Differences at these wavelengths reflect a change in the chemical environments of the six aromatic chromophores (four tyrosines and two phenylalanines). This could be taken either as an indication that the overall tertiary structure of Grx3 is slightly altered or that some aromatic chromophores change from a restrictive and spectroscopically anisotropic environment to a more open and isotropic one allowing the aromatic rings to flip, as would be expected from a more open and dynamic state. Both Tyr6 and Phe56 are in close proximity to Met43 and a point mutation at this position will most likely alter the chemical environment of these two residues and hence the observed spectral differences may reflect changes in the immediate chemical surrounding of Tyr6 and Phe56 and not any overall structural alterations.

\section{The structural effect of the M43V mutation has long-range consequences}

NMR spectroscopy is capable of providing detailed information on many levels of structure, from three-dimensional structures at atomic resolution to specific chemical environments of a given atom provided that sequence-specific resonance assignments are known. As the assignment of reduced wild type Grx3 has been determined within our laboratory [15, 33], we set out to obtain the ${ }^{1} \mathrm{H},{ }^{13} \mathrm{C}$, and ${ }^{15} \mathrm{~N}$ assignments of reduced Grx3(M43V/C65Y) in order to compare structural and dynamic features. To achieve the assignment of reduced Grx3(M43V/C65Y), a series of standard triple-resonance experiments were collected. The subsequent analysis was performed semi-automatically using the GARANT program [34] and confirmed manually. In all spectra, Ala1, Thr10 and Gly35 are missing an observation made previously for the wild-type protein [15]. As a first assessment of the structural similarity of the two proteins, two-dimensional ${ }^{1} \mathrm{H}-{ }^{15} \mathrm{~N}$ HSQC spectra were obtained of both wild type and M43V/C65Y mutant Grx3 proteins. Grx3 contains 78 nonproline residues and a total of 75 backbone amide peaks were observed in each of the wild type and M43V/C65Y spectra. An unexpectedly large number of resonances were shifted relative to the wild type protein due to the Met43 to Val mutation. 
The ${ }^{1} \mathrm{H}$ and ${ }^{15} \mathrm{~N}$ chemical shift deviations $(\Delta \delta)$ are shown in Figures $4 \mathrm{~A}$ and $\mathrm{B}$, respectively. To account for both ${ }^{1} \mathrm{H}$ and ${ }^{15} \mathrm{~N}$ deviations in a single parameter, a weighted statistic (Fig. 4C) was calculated using the formula $\Delta \delta_{\mathrm{AV}}=\left(0.5\left(\delta_{\mathrm{Hmut}}-\delta_{\mathrm{Hwt}}\right)^{2}+0.02\left(\delta_{\mathrm{Nmut}}-\delta_{\mathrm{Nwt}}\right)^{2}\right)^{1 / 2}$ [35]. A total of 41 out of 74 resonances (not including Val43) have experienced significant chemical shift deviations $\left(\Delta \delta_{\mathrm{AV}}>\right.$ $0.03 \mathrm{ppm})$ in the mutant protein; whereof 9 of these have been subjected to extensive deviations $\left(\Delta \delta_{\mathrm{AV}}\right.$ $\geq 0.15 \mathrm{ppm}$, Fig. 4C). It is not surprising that many of these residues are located in the vicinity of Val43 (as discussed above) of the mutant protein, however, residues close to the active site (e.g. Lys8, Thr51, Val52) have also experienced extensive deviations (Fig. 4D). Interestingly, results from molecular dynamics simulations of wild type and mutant Grx3 [14] indicate that Lys8 and Val52 are closer to $\mathrm{S}^{\gamma}$ of Cys11 in the mutant protein, making possible direct and water-mediated hydrogen bonds to this thiolate. These extra hydrogen bonds in Grx3(M43V/C65Y) would contribute to the reduced $\mathrm{p} K_{\mathrm{a}}$ of $\mathrm{S}^{\gamma}$ of Cys11 (wild type and mutant have $\mathrm{p} K_{\mathrm{a}}$ values of 4.9 and 3.8, respectively), affecting the nucleophilic property and enhancing the leaving group ability of the thiolate of this side chain [36]. A total of 32 residues have backbone amides experiencing large chemical shift perturbations $\left(0.03<\Delta \delta_{\mathrm{AV}}<0.15 \mathrm{ppm}\right)$. The positions of these residues are spread over the entire protein. It appears as if the Met43 to Val mutation has an impact on residues throughout the Grx3 molecule, not only in residues in the vicinity of the mutation.

\section{NMR H/D exchange provides insight of increased slow time-scale motion}

The observed differences between the wild type Grx3 and the M43V/C65Y mutant can be a consequence of tertiary structural rearrangements. However, these results may also be rationalized by differences in main chain and side chain dynamics. To probe the slow time-scale motions of proteins, time-resolved H/D backbone amide exchange monitored by NMR has proven to be a useful method [28]. There is evidence that factors limiting amide hydrogen exchange includes the involvement of the amide in a hydrogen bond as well as the solvent accessibility of the amide. Amides participating in secondary structural elements buried inside the protein are then expected to experience slower exchange with solvent than amides not involved in hydrogen bonds or located on the surface. However, a protein is constantly in a state of flux, populating the thermodynamically and kinetically allowed states. The rate of exchange of a particular amide is related to how frequent it accesses more solvent exposed conformations, which is an indirect measure of the motional freedom of that amide [28].

The H/D exchange reaction (Fig. 5) of the wild type and M43V/C65Y mutant backbone amides were followed by collecting a series of ${ }^{15} \mathrm{~N}$ HSQC spectra at different time points after the addition of deuterated water. As seen in Figure 6A, the H/D exchange reaction could be monitored for a total of 42 backbone amides of the wild type protein while only 34 backbone amides could be characterized in the M43V/C65Y mutant. Remarkably, while residual amide protons in the wild type protein were visible for more than 28 days, there were no detectable peaks from the M43V/C65Y mutant after about 6 hours. These observations indicate a structurally more rigid wild type protein, also seen when comparing the conformational stabilities between Grx3 molecules with and without the $\mathrm{M} 43 \mathrm{~V}$ mutation differing by $2.68 \pm 0.14 \mathrm{kcal} \mathrm{mol}^{-1}(\mathrm{Grx3}(\mathrm{C} 14 \mathrm{~S})=-4.74 \pm 0.12$ and

Grx3(C14S/M43V/C65Y) $\left.=-2.06 \pm 0.08 \mathrm{kcal} \mathrm{mol}^{-1}\right)$. To be able to correctly assign peaks having fast exchange, shorter NMR experiments were initially used having poorer spectral resolution.

Consequently, 5 (out of 42) and 4 (out of 34) peaks in the wild type and M43V/C65Y mutant spectra, respectively, could not be distinguished due to chemical shift degeneracy. Nevertheless, when comparing the ratios of $\mathrm{H} / \mathrm{D}$ exchange rates between the wild type and mutant protein, drastic differences are observed. As seen in Figure 6B, 26 residues (not counting those with degenerate chemical shifts) experience somewhat faster dynamics $\left(\mathrm{k}_{\mathrm{M} 43 \mathrm{~V} / \mathrm{C} 65 \mathrm{Y}} / \mathrm{k}_{\mathrm{WT}}<50\right)$. These residues are not confined to a particular area but are spread throughout the Grx3 molecule (Fig. 6C). A total of 6 residues (not including Met/Val 43) have faster dynamics $\left(50<\mathrm{k}_{\mathrm{M} 43 \mathrm{~V} / \mathrm{C} 65 \mathrm{Y}} / \mathrm{k}_{\mathrm{WT}}<150\right)$, while 8 residues experience much faster dynamics $\left(\mathrm{k}_{\mathrm{M} 43 \mathrm{~V} / \mathrm{C} 65 \mathrm{Y}} / \mathrm{k}_{\mathrm{WT}}>150\right)$ in the mutant protein. Interestingly, in contrast to the residues experiencing somewhat faster dynamics, residues having much faster dynamics (except Lys18) are confined to the central $\beta$-sheet core buried inside the protein. These results demonstrate that the Met43 to Val mutation not only has a striking effect on the central $\beta$-sheet core of the Grx3 molecule, but also a global effect on the molecule, increasing the rate at which the 
structure fluctuates between buried and more solvent exposed conformations where amide exchange can occur.

It has previously been argued that the apparent substrate promiscuity of Grx1 might be due to a higher degree of "dynamic plasticity" [16] as it exhibits a more "open” structure relative Grx3 in the area of the active site [14]. The data presented above provides the first direct experimental evidence that the Met43 to Val mutation in Grx3 results in a protein with a greater conformational flexibility. Initial biochemical data investigating the Grx1-like behavior of the Grx3(M43V/C65Y) mutant concluded that an increased $V_{\max }$ and not $K_{\mathrm{m}}$ in conjunction with a lowered active site cysteine redox potential (by $11 \mathrm{mV}$ ) and a lowered $\mathrm{p} K_{\mathrm{a}}$ (by 0.9 units) of the $\mathrm{N}$-terminal active site cysteine was responsible for the altered activity [14]. Our results confirm the lower active site redox potential caused by the M43V mutation. However, in contrast to Porat and co-workers [14], we demonstrate that the Grx3(M43V/C65Y) mutant has acquired a Grx1-like affinity for ribonucleotide reductase not present in wild type Grx3. Although there were no detectable secondary structural perturbations as probed by far-UV CD spectroscopy, both near-UV CD and NMR ${ }^{1} \mathrm{H}^{15} \mathrm{~N}$ correlation data demonstrate that there are differences between the wild type and M43V/C65Y mutant Grx3. These differences could be the result of changes in tertiary structure, however, the H/D exchange measurements point at distinct patterns of residues with dramatically altered behavior where the M43V mutation has had a global effect on the protein, causing the mutant to more frequently access an exposed structure. The lower conformational stability (by $2.68 \pm 0.14 \mathrm{kcal} \mathrm{mol}^{-1}$ ) of the mutant protein compared to the wild type is also an indication that a greater population of exposed molecules is expected in the M43V/C65Y mutant. The Met43 side chain is buried under the second helix in Grx3, where it makes many contacts to surrounding residues. Replacing this methionine with an amino acid containing a smaller or branched side chain could disrupt the inner core, leaving the protein with fewer contacts between these structural units and a greater motional freedom. This increased freedom could be responsible for accommodating a wider variety of substrates. Whether this molecular transformation is a theme found in other proteins remains to be seen. However, multiple sequence alignment [2] reveals that dithiol glutaredoxins in general have various hydrophobic residues in the corresponding Grx3 M43 position, suggesting that this may be a strategy to facilitate substrate promiscuity within this family of proteins. Finally, whether alterations in dynamics alone are responsible for the change in activity or if structural alterations also are involved is the subject of ongoing research, part of which includes the structure determination of the Grx3(M43V/C65Y) mutant using NMR.

\section{FUNDING}

This work was supported by funds from the Karolinska Institutet and Södertörns Högskola (to K.D.B.), a grant GMO41883 from the National Institutes of Health (to J.B.), and grants from the Scandinavia-Japan Sasakawa Foundation and the Boehringer Ingelheim Fonds (to T.H.E.). J.B. is an American Cancer Society Professor. P.G. is supported by the Volkswagen Foundation and by a Grantin-Aid for Scientific Research of the Japan Society for the Promotion of Science. 


\section{REFERENCES}

1 Martin, J. L. (1995) Thioredoxin--a fold for all reasons, Structure. 3, 245-250.

2 Sagemark, J., Elgán, T. H., Bürglin, T. R., Johansson, C., Holmgren, A., and Berndt, K. D. (2007) Redox properties and evolution of human glutaredoxins, Proteins. 68, 879-892.

3 Åslund, F., and Beckwith, J. (1999) Bridge over troubled waters: sensing stress by disulfide bond formation, Cell. 96, 751-753.

4 Shelton, M. D., Chock, P. B., and Mieyal, J. J. (2005) Glutaredoxin: role in reversible protein s-glutathionylation and regulation of redox signal transduction and protein translocation, Antioxid. Redox Signal. 7, 348-366.

5 Gallogly, M. M., Starke, D. W., and Mieyal, J. J. (2009) Mechanistic and kinetic details of catalysis of thiol-disulfide exchange by glutaredoxins and potential mechanisms of regulation, Antioxid. Redox Signal. 11, 1059-1081.

6 Bushweller, J. H., Åslund, F., Wüthrich, K., and Holmgren, A. (1992) Structural and functional characterization of the mutant Escherichia coli glutaredoxin (C14----S) and its mixed disulfide with glutathione, Biochemistry. 31, 9288-9293.

7 Fernandes, A. P., and Holmgren, A. (2004) Glutaredoxins: glutathione-dependent redox enzymes with functions far beyond a simple thioredoxin backup system, Antioxid. Redox Signal. 6, 63-74.

8 Nordstrand, K., Åslund, F., Holmgren, A., Otting, G., and Berndt, K. D. (1999) NMR structure of Escherichia coli glutaredoxin 3-glutathione mixed disulfide complex: implications for the enzymatic mechanism, J. Mol. Biol. 286, 541-552.

9 Vlamis-Gardikas, A., Åslund, F., Spyrou, G., Bergman, T., and Holmgren, A. (1997) Cloning, overexpression, and characterization of glutaredoxin 2, an atypical glutaredoxin from Escherichia coli, J. Biol. Chem. 272, 11236-11243.

10 Åslund, F., Ehn, B., Miranda-Vizuete, A., Pueyo, C., and Holmgren, A. (1994) Two additional glutaredoxins exist in Escherichia coli: glutaredoxin 3 is a hydrogen donor for ribonucleotide reductase in a thioredoxin/glutaredoxin 1 double mutant, Proc. Natl. Acad. Sci. U. S. A. 91, 9813-9817.

11 Prinz, W. A., Åslund, F., Holmgren, A., and Beckwith, J. (1997) The role of the thioredoxin and glutaredoxin pathways in reducing protein disulfide bonds in the Escherichia coli cytoplasm, J. Biol. Chem. 272, 15661-15667.

12 Lillig, C. H., Prior, A., Schwenn, J. D., Åslund, F., Ritz, D., Vlamis-Gardikas, A., and Holmgren, A. (1999) New thioredoxins and glutaredoxins as electron donors of 3'phosphoadenylylsulfate reductase, J. Biol. Chem. 274, 7695-7698.

13 Ortenberg, R., Gon, S., Porat, A., and Beckwith, J. (2004) Interactions of glutaredoxins, ribonucleotide reductase, and components of the DNA replication system of Escherichia coli, Proc. Natl. Acad. Sci. U. S. A. 101, 7439-7444.

14 Porat, A., Lillig, C. H., Johansson, C., Fernandes, A. P., Nilsson, L., Holmgren, A., and Beckwith, J. (2007) The Reducing Activity of Glutaredoxin 3 toward Cytoplasmic Substrate Proteins Is Restricted by Methionine 43, Biochemistry.

15 Åslund, F., Nordstrand, K., Berndt, K. D., Nikkola, M., Bergman, T., Ponstingl, H., Jörnvall, H., Otting, G., and Holmgren, A. (1996) Glutaredoxin-3 from Escherichia coli. Amino acid sequence, 1H AND 15N NMR assignments, and structural analysis, J. Biol. Chem. 271, 67366745.

16 Berardi, M. J., and Bushweller, J. H. (1999) Binding specificity and mechanistic insight into glutaredoxin-catalyzed protein disulfide reduction, J. Mol. Biol. 292, 151-161. Elgán, T. H., and Berndt, K. D. (2008) Quantifying E. coli glutaredoxin-3 substrate specificity using ligand-induced stability, J. Biol. Chem. 283, 32839-32847.

18 Marley, J., Lu, M., and Bracken, C. (2001) A method for efficient isotopic labeling of recombinant proteins, J. Biomol. NMR. 20, 71-75.

19 Gill, S. C., and von Hippel, P. H. (1989) Calculation of protein extinction coefficients from amino acid sequence data, Anal. Biochem. 182, 319-326. 
20 Berardi, M. J., Pendred, C. L., and Bushweller, J. H. (1998) Preparation, characterization, and complete heteronuclear NMR resonance assignments of the glutaredoxin (C14S)ribonucleotide reductase B1 737-761 (C754S) mixed disulfide, Biochemistry. 37, 5849-5857.

21 Pace, C. N., and Scholtz, M. (1997) Measuring the conformational stability of a protein, In Protein Structure: A Practical Approach (Creighton, T. E., Ed.) 2 ed., pp 299-321, Oxford University Press, Eynsham, Oxon.

22 Santoro, M. M., and Bolen, D. W. (1988) Unfolding free energy changes determined by the linear extrapolation method. 1. Unfolding of phenylmethanesulfonyl alpha-chymotrypsin using different denaturants, Biochemistry. 27, 8063-8068.

23 Åslund, F., Berndt, K. D., and Holmgren, A. (1997) Redox potentials of glutaredoxins and other thiol-disulfide oxidoreductases of the thioredoxin superfamily determined by direct protein-protein redox equilibria, J. Biol. Chem. 272, 30780-30786.

24 Lin, T. Y., and Kim, P. S. (1989) Urea dependence of thiol-disulfide equilibria in thioredoxin: confirmation of the linkage relationship and a sensitive assay for structure, Biochemistry. 28, 5282-5287.

25 Bax, A. (1994) Multidimensional nuclear magnetic resonance methods for protein studies, Curr. Opin. Struct. Biol. 4, 738-744.

26 Delaglio, F., Grzesiek, S., Vuister, G. W., Zhu, G., Pfeifer, J., and Bax, A. (1995) NMRPipe: a multidimensional spectral processing system based on UNIX pipes, J. Biomol. NMR. 6, 277293.

27 Bartels, C., Billeter, M., Güntert, P., and Wüthrich, K. (1996) Automated sequence-specific NMR assignment of homologous proteins using the program GARANT, J. Biomol. NMR. 7, 207-213.

28 Dempsey, C. E. (2001) Hydrogen exchange in peptides and proteins using NMR spectroscopy, Prog. Nucl. Magn. Reson. Spectrosc. 39, 135-170.

29 Bartels, C., Xia, T., Billeter, M., Güntert, P., and Wüthrich, K. (1995) The program XEASY for computer-supported NMR spectral analysis of biological macromolecules, J. Biomol. NMR. 6, 1-10.

30 Nordstrand, K., Sandström, A., Åslund, F., Holmgren, A., Otting, G., and Berndt, K. D. (2000) NMR structure of oxidized glutaredoxin 3 from Escherichia coli, J. Mol. Biol. 303, 423-432.

31 Tamarit, J., Belli, G., Cabiscol, E., Herrero, E., and Ros, J. (2003) Biochemical characterization of yeast mitochondrial Grx5 monothiol glutaredoxin, J. Biol. Chem. 278, 25745-25751.

32 Saaranen, M. J., Salo, K. E., Latva-Ranta, M. K., Kinnula, V. L., and Ruddock, L. W. (2009) The C-terminal active site cysteine of Escherichia coli glutaredoxin 1 determines the glutathione specificity of the second step of peptide deglutathionylation, Antioxid. Redox Signal. 11, 1819-1828.

33 Sagemark, J., Güntert, P., and Berndt, K. D. (2008) In preparation.

34 Bartels, C., Güntert, P., Billeter, M., and Wüthrich, K. (1997) GARANT - A general algorithm for resonance assignment of multidimensional nuclear magnetic resonance spectra, J. Comp. Chem. 18, 139-149.

35 Grzesiek, S., Stahl, S. J., Wingfield, P. T., and Bax, A. (1996) The CD4 determinant for downregulation by HIV-1 Nef directly binds to Nef. Mapping of the Nef binding surface by NMR, Biochemistry. 35, 10256-10261.

36 Shaked, Z., Szajewski, R. P., and Whitesides, G. M. (1980) Rates of thiol-disulfide interchange reactions involving proteins and kinetic measurements of thiol pKa values, Biochemistry. 19, 4156-4166. 


\section{TABLE 1}

Table 1 Parameters ( \pm standard deviation) obtained from ligand-induced stability measurements using urea unfolding monitored by $C D$ at $222 \mathrm{~nm}$

The unfolding curves of nonbound and RRp mixed disulfide forms of Grx1 and Grx3 (both wild type and $\mathrm{M} 43 \mathrm{~V} / \mathrm{C} 65 \mathrm{Y}$ mutant) were fitted to Equation 1 by nonlinear regression analysis. The parameters from the unfolding of reduced and oxidized wild type Grx3 M43V/C65Y, used for redox potential determination using thermodynamic linkage, are also included. Here, $\Delta \Delta G_{1}$ is the free energy contribution upon ligand binding or disulfide formation relative nonbound/reduced $G r \times 1$ and $G r \times 3 ; \Delta \Delta G_{2}$ is the free energy contribution of noncovalent interactions between ligand and protein; [Urea $]_{1 / 2}$ is the midpoint of the urea unfolding curve; $m_{\text {trans }}$ is the slope in the transition region of the unfolding curve; $n . a$. , not applicable. ${ }^{1}$ These values are from [17].

\begin{tabular}{|c|c|c|c|c|c|}
\hline Protein-(mixed disulfide) & $\begin{array}{c}\Delta \mathrm{G}_{\mathrm{H} 2 \mathrm{O}}^{\mathrm{Fold}} \\
\left(\mathrm{kcal} \mathrm{mol}^{-1}\right)\end{array}$ & $\begin{array}{c}\Delta \Delta \mathrm{G}_{1} \\
\left(\mathrm{kcal} \mathrm{mol}^{-1}\right)\end{array}$ & $\begin{array}{c}\Delta \Delta \mathrm{G}_{2} \\
\left(\mathrm{kcal} \mathrm{mol}^{-1}\right)\end{array}$ & $\begin{array}{l}{[\text { Urea }]_{1 / 2}} \\
\text { (M) }\end{array}$ & $\begin{array}{c}m_{\text {trans }} \\
\left(k c a l \mathrm{~mol}^{-1} M^{-1}\right)\end{array}$ \\
\hline Grx3(C14S) nonbound & $-4.74 \pm 0.12$ & n.a. & $-2.61 \pm 0.15$ & $3.85 \pm 0.15$ & $-1.23 \pm 0.03$ \\
\hline 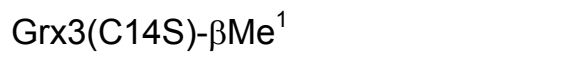 & $-2.13 \pm 0.09$ & $2.61 \pm 0.15$ & n.a. & $1.38 \pm 0.07$ & $-1.54 \pm 0.04$ \\
\hline Grx3(C14S)-RRp & $-4.70 \pm 0.14$ & $0.04 \pm 0.18$ & $-2.57 \pm 0.17$ & $3.79 \pm 0.15$ & $-1.24 \pm 0.04$ \\
\hline Grx3(C14S)-SG ${ }^{1}$ & $-5.20 \pm 0.10$ & $-0.46 \pm 0.16$ & $-3.07 \pm 0.13$ & $5.42 \pm 0.15$ & $-0.96 \pm 0.02$ \\
\hline Grx3(C14S/M43V/C65Y) nonbound & $-2.06 \pm 0.08$ & . & $-2.68 \pm 0.08$ & $1.55 \pm 0.15$ & $-1.33 \pm 0.03$ \\
\hline Grx3(C14S/M43V/C65Y)- $\beta M e$ & $0.62 \pm 0.01$ & $2.68 \pm 0.08$ & n.a. & $-0.37 \pm 0.12$ & $-1.66 \pm 0.07$ \\
\hline Grx3(C14S/M43V/C65Y)-RRp & $-3.57 \pm 0.09$ & $-1.51 \pm 0.12$ & $-4.19 \pm 0.09$ & $2.95 \pm 0.10$ & $-1.21 \pm 0.03$ \\
\hline Grx3(C14S/M43V/C65Y)-SG & $-3.36 \pm 0.06$ & $-1.30 \pm 0.10$ & $-3.98 \pm 0.06$ & $2.42 \pm 0.06$ & $-1.39 \pm 0.02$ \\
\hline Grx1(C14S) nonbound & $-3.60 \pm 0.12$ & n.a. & $-2.82 \pm 0.12$ & $2.90 \pm 0.13$ & $-1.24 \pm 0.04$ \\
\hline $\operatorname{Grx1(C14S)-\beta Me}$ & $8 \pm 0.01$ & $2.82 \pm 0.12$ & n.a. & $0.93 \pm 0.03$ & $-0.84 \pm 0.02$ \\
\hline Grx1(C14S)-RRp & $-5.50 \pm 0.17$ & $-1.90 \pm 0.21$ & $-4.72 \pm 0.17$ & $5.85 \pm 0.26$ & $-0.94 \pm 0.03$ \\
\hline $\operatorname{Grx1}(\mathrm{C} 14 \mathrm{~S})-\mathrm{SG}^{1}$ & 14 & $-0.03 \pm 0.18$ & $-2.85 \pm 0.18$ & $3.99 \pm 0.23$ & $-0.91 \pm 0.04$ \\
\hline Grx3(M43V/C65Y) reduced & $-3.01 \pm 0.04$ & n.a. & n.a. & $2.43 \pm 0.07$ & $-1.24 \pm 0.03$ \\
\hline Grx3(M43V/C65Y) oxidized & $-2.55 \pm 0.06$ & $0.46 \pm 0.07$ & n.a. & $1.81 \pm 0.05$ & $-1.41 \pm 0.02$ \\
\hline
\end{tabular}




\section{FIGURE LEGENDS}

Figure 1 Ligand-induced stability effects upon Grx1 and Grx3 (wild type and M43V/C65Y) binding to ribonucleotide reductase B1-peptide.

Urea unfolding reactions monitored by CD spectroscopy at $222 \mathrm{~nm}$ of nonbound and ribonucleotide reductase B1 peptide (RRp) bound forms of Grx1 and 3, represented by the fraction of unfolded protein $\left(f_{u}\right)$ : Grx1(C14S) in nonbound $(\boldsymbol{\Delta})$ and bound $(\Delta)$ forms, Grx3(C14S) in nonbound $(\bullet)$ and bound $(\circ)$ forms, and Grx3(C14S/M43V/C65Y) in nonbound ( $(\bullet)$ and bound $(\square)$ forms. The data were fitted (solid lines) to Eq. 1 by nonlinear regression analysis.

Figure 2 Stability of reduced and oxidized Grx3(M43V/C65Y) monitored by CD spectroscopy. Urea unfolding curves of reduced ( $\odot$ ) and oxidized ( $\square$ ) Grx3(M43V/C65Y), monitored by CD spectroscopy at $222 \mathrm{~nm}$. For graphical comparison, the raw CD signal was converted into fraction unfolded protein $\left(f_{u}\right)$. The inset shows (left) a thermodynamic linkage analysis based on the relative Gibbs energies for native $(\mathrm{N})$ and unfolded $(\mathrm{U})$ redox states of a protein. To the right, the analysis applied on Grx3(M43V/C65Y). The Gibbs free energy of disulfide bond formation in the unfolded state $\left(1.01 \mathrm{kcal} \mathrm{mol}^{-1}\right)$ is assumed to be identical to the wild type protein.

Figure 3 Structural differences between various mutant forms of Grx1 and Grx3 as probed by CD spectroscopy.

Smoothed near-UV CD spectra of reduced Grx1 and 3 are shown. The insets depict far-UV CD spectra of each protein having the units $\Delta \varepsilon$ in $\mathrm{M}^{-1} \mathrm{~cm}^{-1}$. (A) Spectra of wild type Grx3 (solid line), M43V/C65Y (dotted line), C14S (broken line) and the C14S/M43V/C65Y mutant (broken/dotted line). (B) Spectra of wild type Grx1 (solid line) and its C14S mutant (dotted line).

Figure 4 Chemical shift deviations between Grx3 wild type and M43V/C65Y mutant.

Chemical shift deviations $\left(\Delta \delta_{1 \mathrm{H} / 15 \mathrm{Nmut}}-\Delta \delta_{1 \mathrm{H} / 15 \mathrm{Nwt}}\right)$, from $2 \mathrm{D}{ }^{1} \mathrm{H}^{-15} \mathrm{~N}$ HSQC spectra of Grx3 wild type and M43V/C65Y mutant, plotted as a function of residue number. The secondary structure of wild type Grx3 [30] is presented above the graphs. The resonances from prolines (*) and Ala1, Thr10 and Gly35 ( ${ }^{\circ}$ ) were not observed in the spectra from both wild type and mutant Grx3. (A) ${ }^{1} \mathrm{H}$ chemical shift deviations. (B) ${ }^{15} \mathrm{~N}$ deviations. (C) Weighted chemical shift deviations accounting for both backbone proton and nitrogen resonances were calculated using the formula $\Delta \delta_{\mathrm{AV}}=\left(0.5\left(\delta_{\mathrm{Hmut}}-\delta_{\mathrm{Hwt}}\right)^{2}\right.$ $\left.+0.02\left(\delta_{\mathrm{Nmut}}-\delta_{\mathrm{Nwt}}\right)^{2}\right)^{1 / 2}$ [35] and categorized into large $\left(0.03<\Delta \delta_{\mathrm{AV}}<0.15 \mathrm{ppm}\right)$, and extensive $\left(\Delta \delta_{\mathrm{AV}}\right.$ $\geq 0.15 \mathrm{ppm}$ ) chemical shift perturbations as indicated by dotted grey lines. For graphical purposes the graph has been cut at $\Delta \delta_{\mathrm{AV}}=0.2 \mathrm{ppm}$. (D) Large (blue balls) and extensive (red balls) chemical shift perturbations mapped onto the oxidized wild type Grx3 structure.

\section{Figure 5 Representative NMR H/D exchange plots.}

Examples of H/D exchange plots of (A) Val26, (B) Ser22, and (C) Glu4 exhibiting fast $(0.102 \pm 0.002$ $\left.\min ^{-1}\right)$, intermediate $\left(1.06 \cdot 10^{-3} \pm 0.08 \cdot 10^{-3} \mathrm{~min}^{-1}\right)$ and slow $\left(0.116 \cdot 10^{-3} \pm 0.003 \cdot 10^{-3} \mathrm{~min}^{-1}\right)$ rates, respectively. The insets show the respective plots from the M43V/C65Y mutant with rates of $0.136 \pm$ 0.007 (Val26), $0.074 \pm 0.002$ (Ser22), and $0.028 \pm 0.002$ (Glu4) $\mathrm{min}^{-1}$, respectively.

Figure 6 Plot of $H / D$ exchange rate values versus residue number.

(A) Plot of $-\log (\mathrm{k})$ values of wild type Grx3 (filled grey boxes) and its M43V/C65Y mutant (black boxes). Grey and black asterisks indicate uncertainty due to peak overlap in the wild type and M43V/C65Y spectra, respectively. A filled black circle indicates backbone amides that, in contrast to the wild type protein, could not be detected within the timeframe of the NMR measurement. (B) Ratios of the M43V/C65Y mutant and wild type rate constants. Here a black asterisk indicates an uncertain value due to peak overlap while a filled black circle indicate that the ratio is based on a $\mathrm{k}$ value of $1 \mathrm{sec}^{-1}$ for the M43V/C65Y mutant. Grey dotted lines separate residues of the M43V/C65Y mutant with slightly faster $\left(\mathrm{k}_{\mathrm{M} 43 \mathrm{~V} / \mathrm{C} 65 \mathrm{Y}} / \mathrm{k}_{\mathrm{WT}}<50\right)$, faster (between 50 and 150) and much faster $(>150)$ $\mathrm{H} / \mathrm{D}$ exchange rates than the wild type protein. In (C), the residues representing the slightly faster 
B Biochemical Journal Immediate Publication. Published on 06 Jul 2010 as manuscript BJ20100289

(blue balls), faster (brown balls), and much faster (red balls) H/D exchange rates have been mapped out on the oxidized wild type Grx3 structure [30]. The secondary structure of the oxidized wild type Grx3 is shown above the graphs. 
B Biochemical Journal Immediate Publication. Published on 06 Jul 2010 as manuscript BJ20100289

FIGURE 1

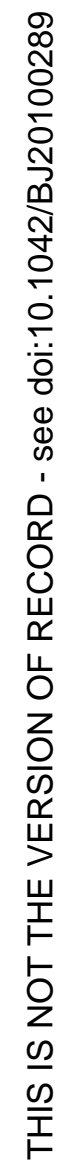

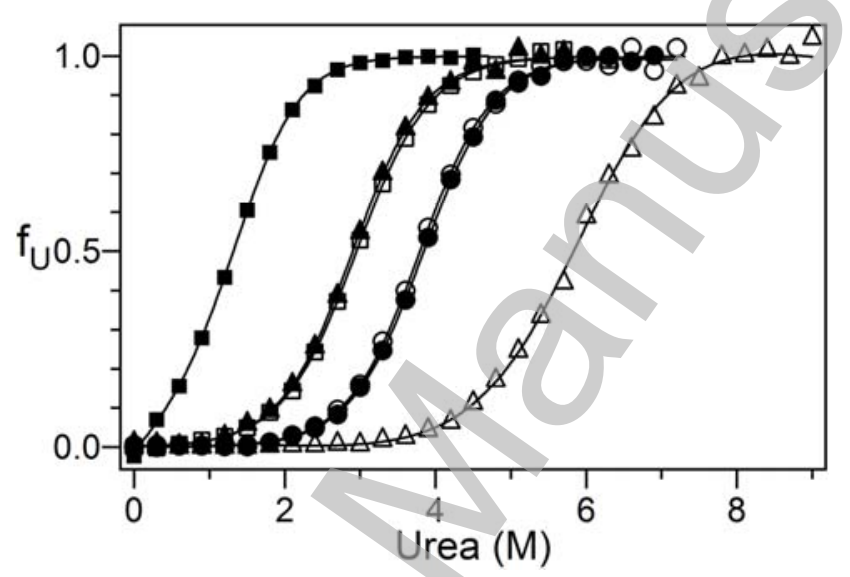


FIGURE 2

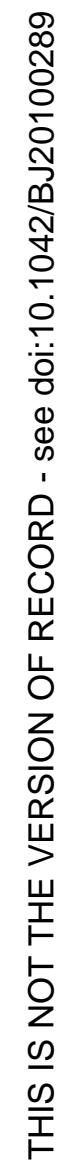

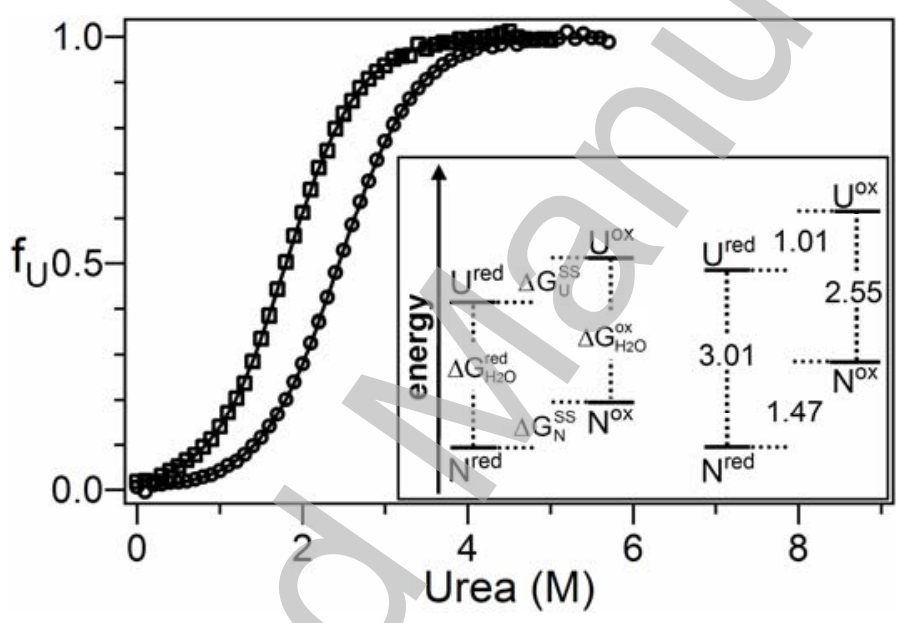


Biochemical Journal Immediate Publication. Published on 06 Jul 2010 as manuscript BJ20100289

FIGURE 3

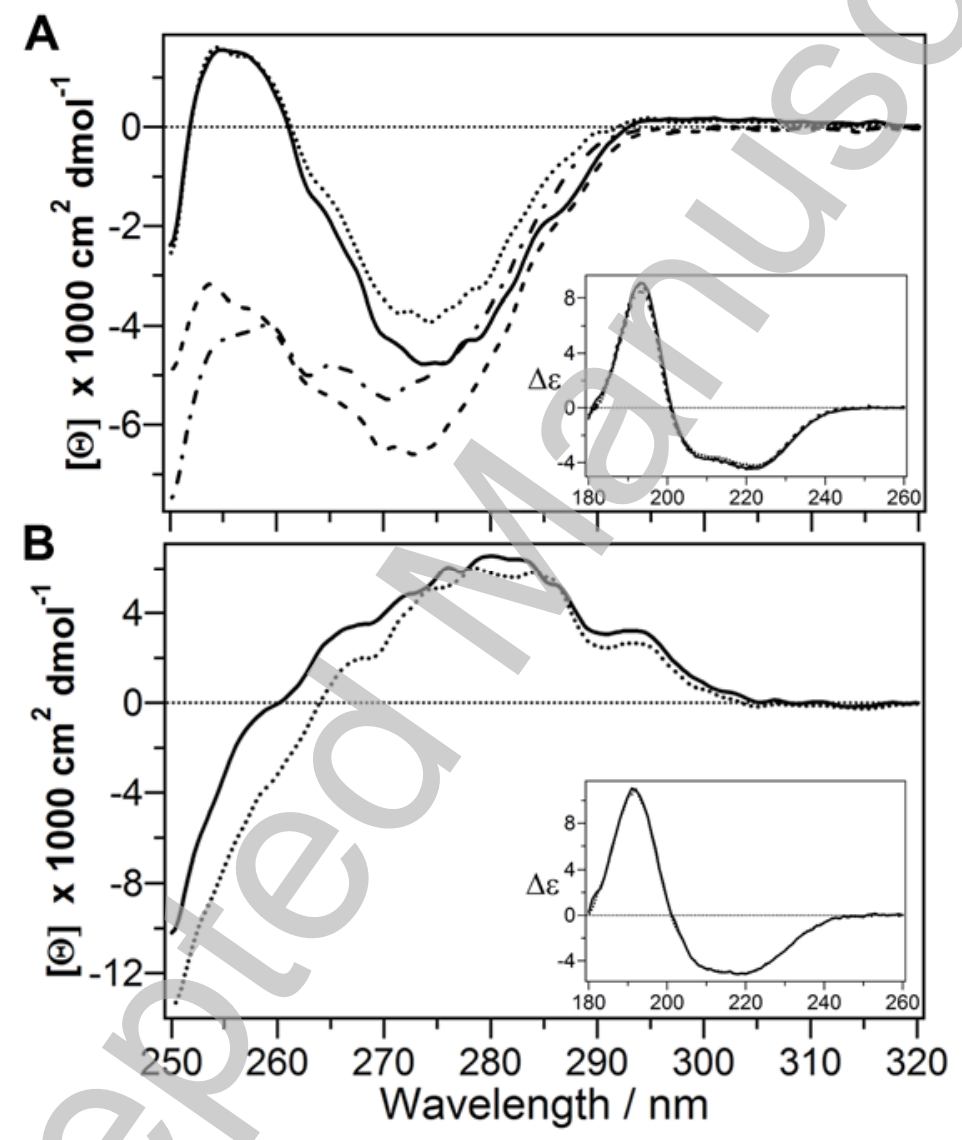


Biochemical Journal Immediate Publication. Published on 06 Jul 2010 as manuscript BJ20100289

FIGURE 4

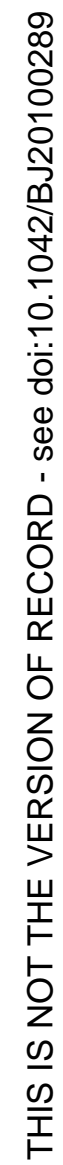
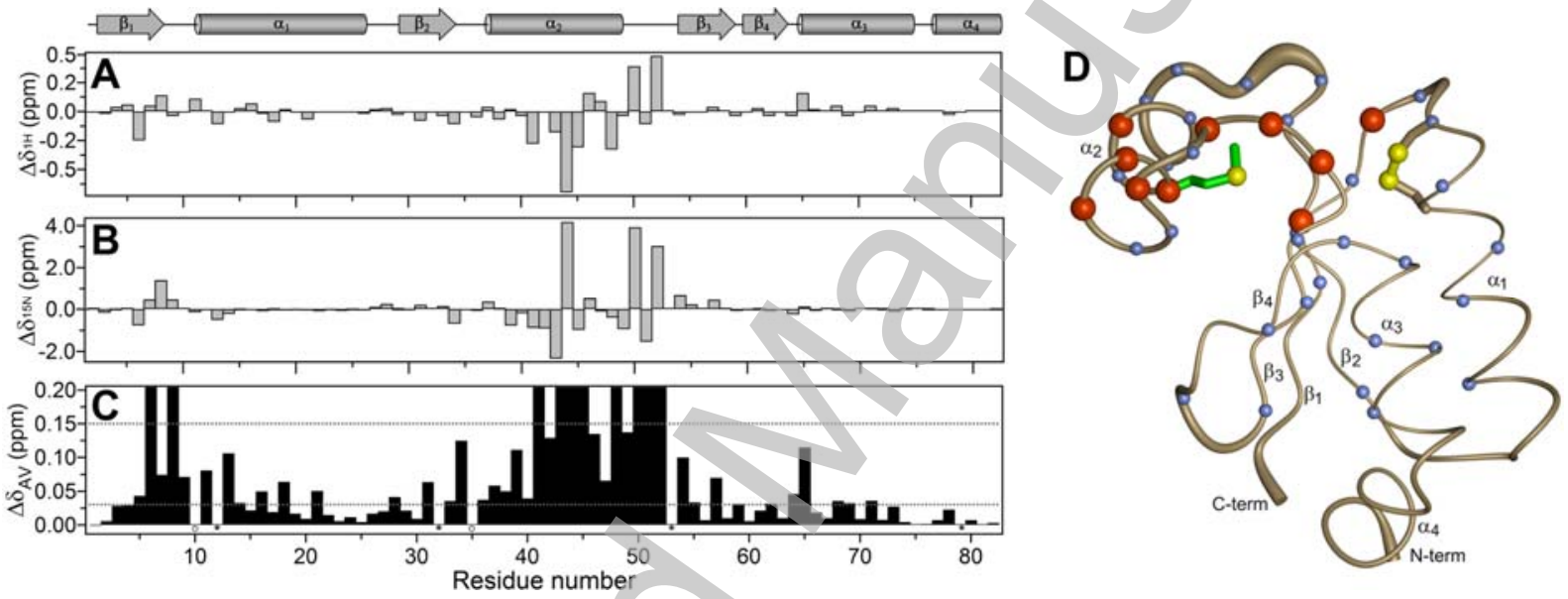
Biochemical Journal Immediate Publication. Published on 06 Jul 2010 as manuscript BJ20100289

FIGURE 5
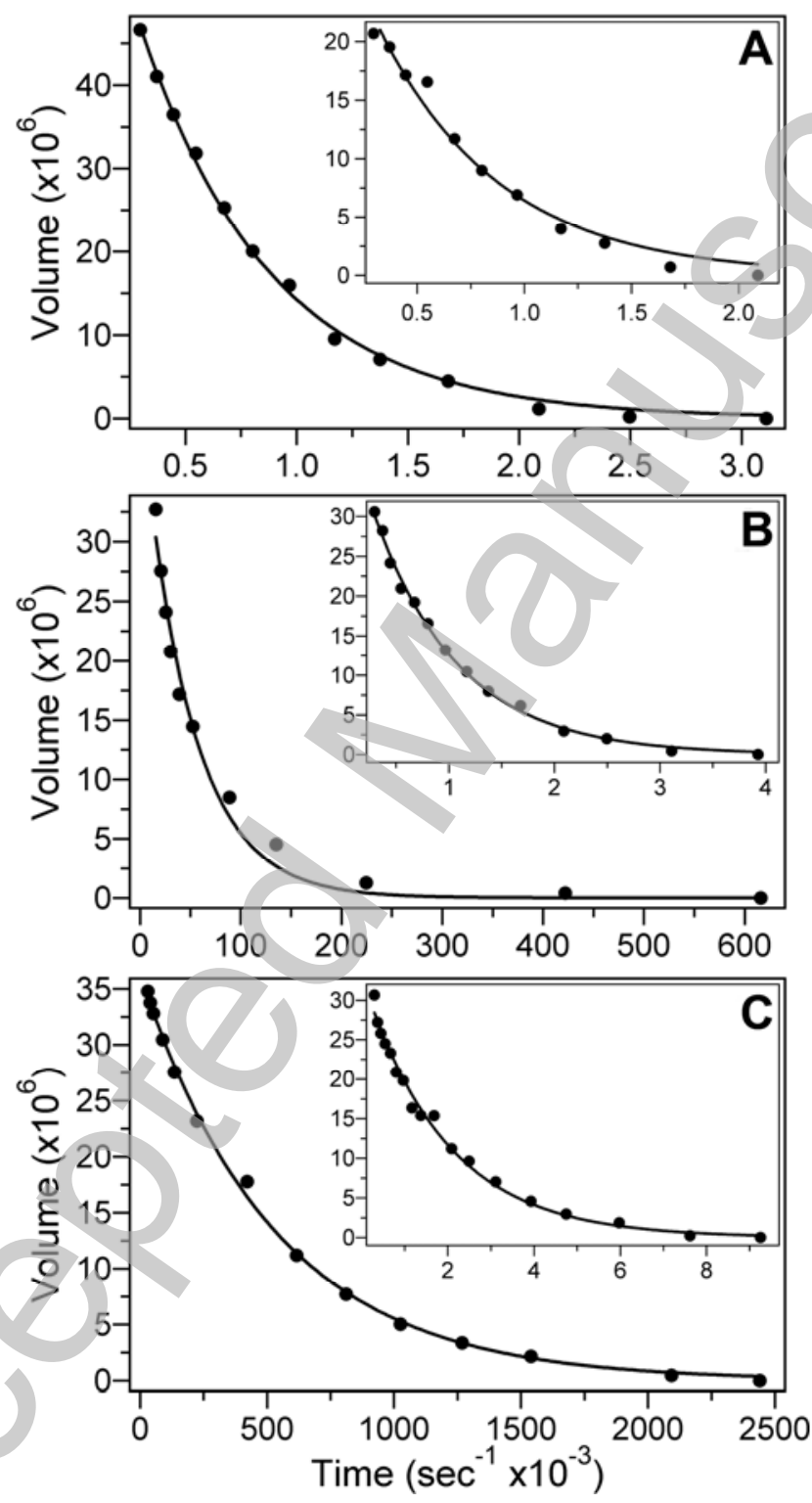
FIGURE 6

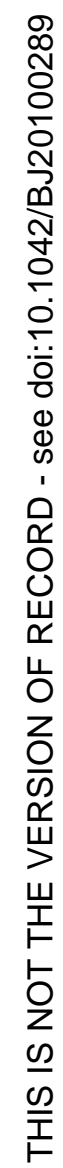

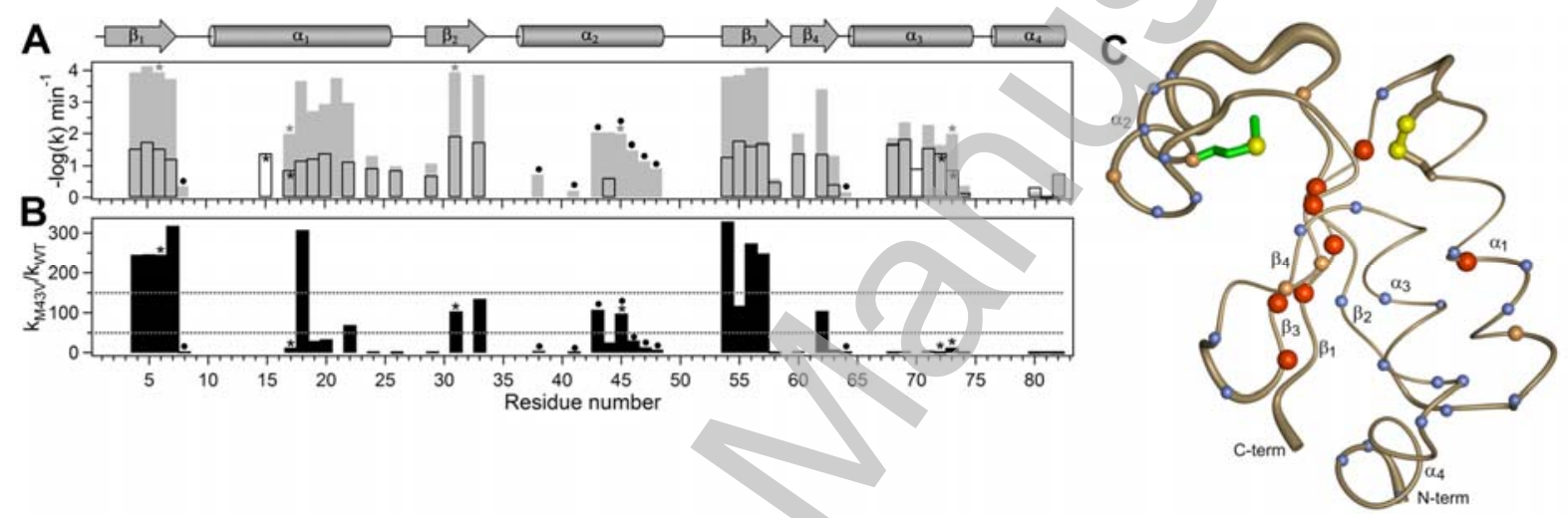

